\title{
Visible light degradation of textile effluent using nanostructured $\mathrm{TiO}_{2} / \mathrm{Ag} / \mathrm{CuO}$ photocatalysts
}

\author{
N. Karthikeyan ${ }^{1,2}$, V. Narayanan ${ }^{3}$ and A. Stephen ${ }^{1}$ \\ ${ }^{1}$ Department of Nuclear Physics, University of Madras, Guindy Campus, Chennai, India \\ ${ }^{2}$ Department of Physics, The Open University of Sri Lanka, Nawala, Nugegoda, Sri Lanka \\ ${ }^{3}$ Department of Inorganic Chemistry, University of Madras, Guindy Campus, Chennai, India \\ karthikppt@gmail.com,vnnara@yahoo.co.in,stephen_arum@hotmail.com
}

PACS 62.23.St, 42.70.Qs, 87.85.Rs

DOI 10.17586/2220-8054-2016-7-4-695-698

\begin{abstract}
$\mathrm{TiO}_{2}, \mathrm{Ag}$ and $\mathrm{CuO}$ nanomaterials, and nanostructured $\mathrm{TiO}_{2} / \mathrm{Ag} / \mathrm{CuO}$ photocatalytic materials coupled in different weight percentages were synthesized. The prepared materials were characterized by XRD, SEM, EDX and UV-Vis diffuse reflectance spectroscopy. Photocatalytic degrading capabilities of the pure, as well as the nanostructured $\mathrm{TiO}_{2} / \mathrm{Ag} / \mathrm{CuO}$ photocatalytic materials were tested on the dye effluent collected from the textile industries. The samples collected during the photocatalytic degradation of textile dye effluent were studied with UV-Vis spectroscopy. The nanostructured $\mathrm{TiO}_{2} / \mathrm{Ag} / \mathrm{CuO}$ photocatalyst with the composition of 80:10:10 weight percentage exhibited remarkable performance. Coupling of $\mathrm{Ag}$ metal nanoparticles and narrow bandgap $\mathrm{CuO}$ semiconductor nanomaterial to the wide bandgap $\mathrm{TiO}_{2}$ semiconductor nanomaterial was found to modify the operative bandgap of the system and generate electron-hole pairs under visible light irradiation. The coupled $\mathrm{TiO}_{2} / \mathrm{Ag} / \mathrm{CuO}$ system facilitates improved electron transfer to the adsorbed molecules, and thus the system improves the photocatalytic degradation of dyes by enhanced redox mechanism.
\end{abstract}

Keywords: Coupled $\mathrm{TiO}_{2} / \mathrm{Ag} / \mathrm{CuO}$, Nanostructured photocatalysts, bandgap, degradation of textile effluents, advanced oxidation process.

Received: 5 February 2016. Revised: 18 April 2016.

\section{Introduction}

In 1972, Fujishima and Honda found that $\mathrm{TiO}_{2}$ could be used as catalytic electrode in a photo-electrolysis cell to decompose water into $\mathrm{H}_{2}$ and $\mathrm{O}_{2}$, without applying an external voltage [1]. Further researches established the use of $\mathrm{TiO}_{2}$ for photo-assisted degradation of organic compounds and reduction of inorganic compounds. Researches on purification of polluted water gained greater importance with ever increasing need to purify the industrial effluents as well as the contaminated water resources by the industrial waste streams which often created serious health and environmental problems. Among the many, textile effluents play significant role in polluting the water resources and the environment. Traditional effluent purification processes often produce end products with carcinogenic compounds, which require further treatment for complete purification. The photocatalytic degradation of textile effluents using nanophotocatalysts through advanced oxidation process is one of the recent scientific explorations that gain importance mainly due to its ability to produce harmless end products [2-4].

Titania is a semiconductor with bandgap energies in the range of $3.2-3.4 \mathrm{eV}$, and hence could produce electron-hole pairs upon UV region photon irradiation. When these photogenerated charge carriers migrate to the surface without recombining, they could interact with the adsorbed water and oxygen molecules to produce radical species. These radicals strike any adsorbed organic dyes and lead to complete or selective degradation. Repeated efforts are being made by the researchers to trigger this degradation process under visible light irradiation, to make the process very economical by using abundantly-available solar light in various photocatalytic applications. Efficient photogeneration of electron - hole pairs, prevention of their recombination and reduction of specific surface area of the particles of the photocatalysts are the key factors in increasing the efficiency of photocatalytic activity. Several researchers have proven that coupling of semiconductors with noble metals and other semiconductor materials at nanoscales plays significant role in modifying the above factors [5-9].

In this exploration, $\mathrm{TiO}_{2}, \mathrm{Ag}$ and $\mathrm{CuO}$ nanomaterials, and nanostructured $\mathrm{TiO}_{2} / \mathrm{Ag} / \mathrm{CuO}$ photocatalysts coupled in different weight percentages were synthesized under optimized conditions $[10,11]$ and tested for their degradation efficiency on a model dye and also on an effluent collected from textile industries in Tamil Nadu, India.

\section{Experimental methods}

Titania was synthesized using the sol-gel method, by dissolving the precursor titanium (IV) isopropoxide in isopropanol under continuous stirring at room temperature, and then by adding citric acid as the chelating agent mixed with deionized water. $\mathrm{Ag}$ and $\mathrm{CuO}$ were synthesized via thermal decomposition method by heat treatment 
of silver acetate and copper acetate, separately in alumina crucibles, by rising the temperature up to $300{ }^{\circ} \mathrm{C}$ in steps of $4{ }^{\circ} \mathrm{C} / \mathrm{min}$. Then, the respective polycrystalline nanoparticles were synthesized by annealing the asprepared samples at the optimized temperature of $450{ }^{\circ} \mathrm{C}$ for 30 minutes. Details for this protocol were reported elsewhere [12]. Then, the coupled $\mathrm{TiO}_{2} / \mathrm{Ag} / \mathrm{CuO}$ photocatalysts were synthesized by taking the as prepared samples in three different weight percentages, viz. 80:15:05. 80:10:10 and 80:05:15, grinding them well for 2 hrs, and then annealing at $450{ }^{\circ} \mathrm{C}$ for $30 \mathrm{~min}$.

X-ray diffraction studies were carried out on RICH SEIFERT, Germany (model 3000) diffractometer using $\mathrm{Cu}-\mathrm{K}_{\alpha 1}$ radiation $(\lambda=1.54056 \AA), 30 \mathrm{kV}$ voltage, and $10 \mathrm{~mA}$ current. Surface morphology and elemental composition were carried out using QUANTA 200 FEG high resolution scanning electron microscopy (HR-SEM) and energy-dispersive X-ray spectroscopy (EDX). The optical properties of the samples in UV and Visible ranges were investigated using CARY 5E UV-VIS-NIR spectrophotometer.

\section{Results and discussions}

\subsection{Phase and structure confirmation}

Figure 1 shows the powder XRD patterns of the $\mathrm{TiO}_{2}, \mathrm{Ag}$, and $\mathrm{CuO}$, and that of coupled $\mathrm{TiO} / \mathrm{Ag} / \mathrm{CuO}$ samples prepared at weight percentages 80:05:15, 80:10:10 and 80:15:05, and annealed at $450{ }^{\circ} \mathrm{C}$. The primary diffraction peaks of the $\mathrm{TiO}_{2}$ were indexed to anatase phase Titania with tetragonal crystal structure, and the values well matched with the JCPDS card 84-1285. The calculated lattice parameter values are: $a=b=3.784 \AA$ and $c=9.561 \AA$.

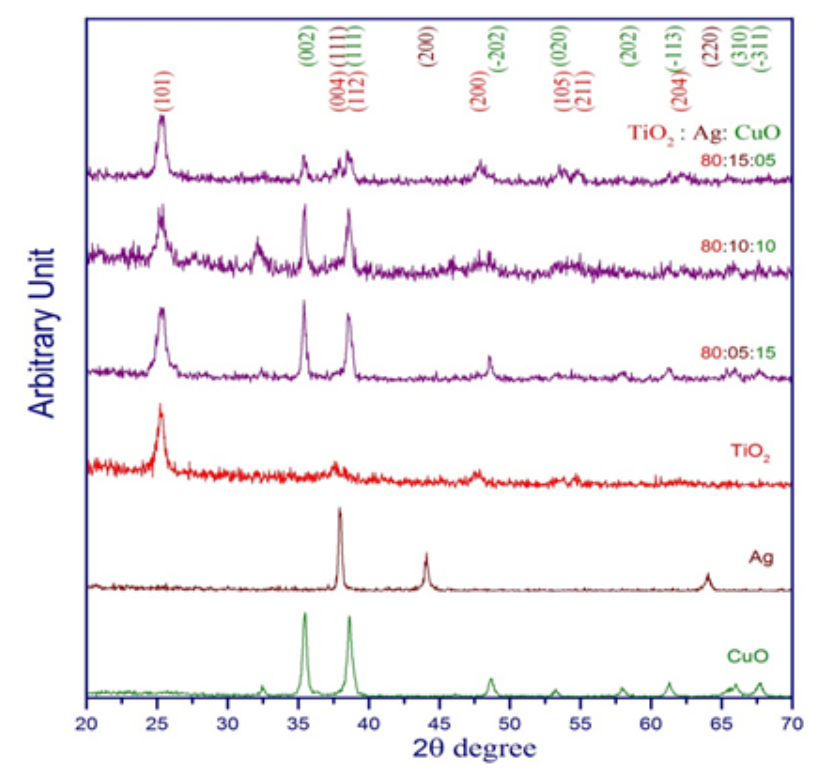

FIG. 1. XRD patterns of all the prepared samples, annealed at $450{ }^{\circ} \mathrm{C}$ for $30 \mathrm{~min}$.

The characteristic peaks of the $\mathrm{CuO}$ were indexed to monoclinic structure and the values are in good agreement with the reported values in the JCPDS card 89-5896. The determined lattice parameters are: $a=4.683 \AA$, $b=3.424 \AA$ and $c=5.129 \AA$.

The diffraction peaks of the prepared sample Ag were indexed to cubic structure and could be matched well with the JCPDS card number 03-0921. The calculated lattice parameters are: $a=b=c=3.914 \AA$.

The crystallite sizes were estimated using the Scherrer's formula, and the estimated average crystallite sizes ranged from 9 to $64 \mathrm{~nm}$. No significant peak shifts were observed in the XRD patterns of the coupled systems.

The HRSEM images, as shown in Fig. 2, of the coupled photocatalysts reveal irregularly-shaped particles, which are agglomeration of the tiny spherically shaped particles. The average particle sizes of the isolated spheres were in the range from 25 to $80 \mathrm{~nm}$. The EDX analysis confirmed the elemental composition in the respective coupled photocatalysts. 

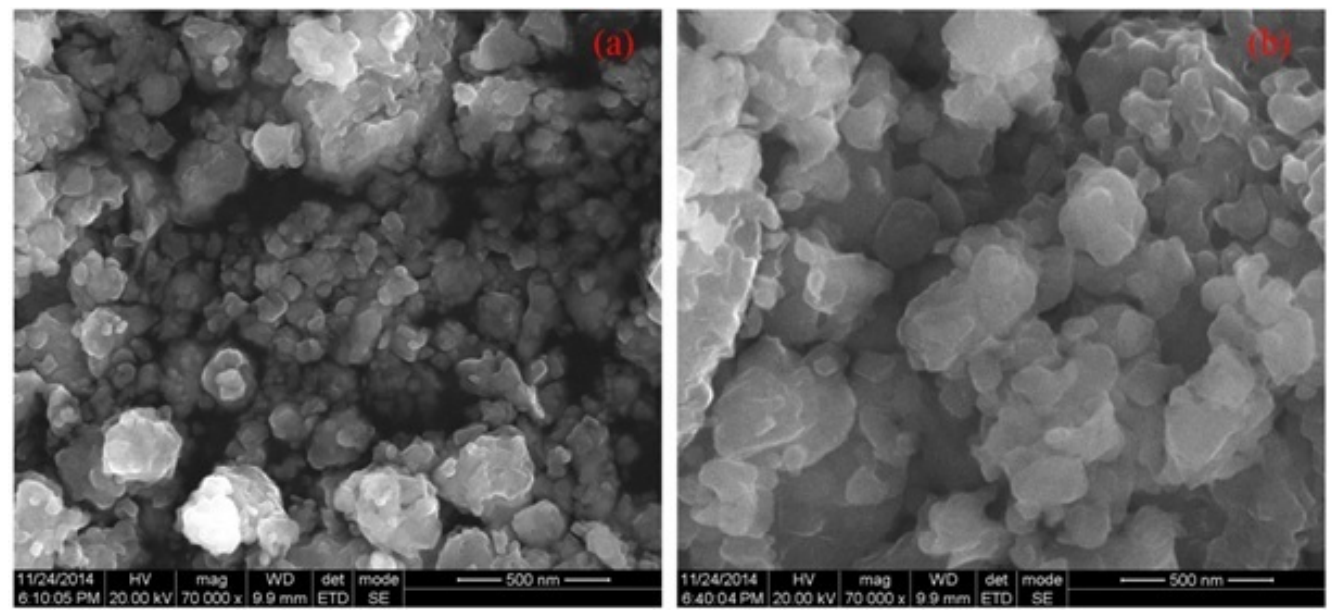

FIG. 2. HRSEM images $\mathrm{TiO}_{2} / \mathrm{Ag} / \mathrm{CuO}$ at wt\%: (a) 80:10:10; (b) 80:15:05

\subsection{Optical properties and bandgap energies}

UV-Vis Diffuse Reflectance spectrum of the prepared photocatalytic samples $\mathrm{TiO}_{2}, \mathrm{TiO}_{2} / \mathrm{Ag} / \mathrm{CuO}$ (80:15:05), $\mathrm{TiO}_{2} / \mathrm{Ag} / \mathrm{CuO}(80: 10: 10)$ and $\mathrm{TiO}_{2} / \mathrm{Ag} / \mathrm{CuO}(80: 05: 15)$ are shown in Fig. 3. The absorption edge of the pure $\mathrm{TiO}_{2}$ was in the UV region. However, red shifts were observed for the coupled $\mathrm{TiO}_{2} / \mathrm{Ag} / \mathrm{CuO}$ photocatalysts prepared at three different weight percentages 80:15:05, 80:10:10 and 80:05:15 and their absorption edges have fallen in the visible region.

The estimated optical band gap energies of pure $\mathrm{TiO}_{2}$ as well as those of the coupled $\mathrm{TiO}_{2} / \mathrm{Ag} / \mathrm{CuO}$ nanophotocatalysts prepared at three different weight percentages 80:15:05, 80:10:10 and 80:05:15 are shown in Table 1 .

TABLE 1. Optical band gap energies of the prepared photocatalysts

\begin{tabular}{|c|c|}
\hline Photocatalysts & Band gap \\
\hline $\mathrm{TiO}_{2}$ & $3.3 \mathrm{eV}$ \\
\hline $\mathrm{TiO}_{2} / \mathrm{Ag} / \mathrm{CuO}(80: 05: 15)$ & $3.0 \mathrm{eV}$ \\
\hline $\mathrm{TiO}_{2} / \mathrm{Ag} / \mathrm{CuO}(80: 10: 10)$ & $2.9 \mathrm{eV}$ \\
\hline $\mathrm{TiO}_{2} / \mathrm{Ag} / \mathrm{CuO}(80: 15: 05)$ & $3.0 \mathrm{eV}$ \\
\hline
\end{tabular}

\subsection{Photocatalytic degradation test results}

All the photocatalysts were tested for their decoloration efficiency on the methylene blue (MB) dye under visible irradiations and the results are shown in Fig. 4. The photocatalyst $\mathrm{TiO}_{2} / \mathrm{Ag} / \mathrm{CuO}$ synthesized at 80:10:10 wt \% showed best efficiency with more than $75 \%$ of decoloration in 120 minutes under visible light irradiation.

Then the best photocatalyst $\mathrm{TiO}_{2} / \mathrm{Ag} / \mathrm{CuO}(80: 10: 10)$ was employed in the degradation of the textile effluent and the results are shown in Fig. 5. More than $80 \%$ decoloration of the textile effluent was achieved in 240 minutes under visible light irradiation.

\section{Conclusions}

$\mathrm{TiO}_{2}, \mathrm{Ag}$ and $\mathrm{CuO}$, and coupled $\mathrm{TiO}_{2} / \mathrm{Ag} / \mathrm{CuO}$ photocatalysts at three different weight percentages 80:05:15, 80:10:10 and 80:15:05 were synthesized. Their structural, morphological and optical properties were analyzed with various characterization techniques. Among the prepared photocatalysts, $\mathrm{TiO}_{2} / \mathrm{Ag} / \mathrm{CuO}(80: 10: 10)$ gave the best decoloration (about $79 \%$ ) of MB in 2 hours under visible light irradiation. This is in agreement with the results obtained from the optical property studies. The best photocatalyst effectively degraded the textile effluent with an efficiency of about $82 \%$ of decoloration in 4 hours under visible light irradiation. Inclusion of optimal amount of $\mathrm{CuO}$ and $\mathrm{Ag}$ was found to modify the band gap significantly and make the photocatalyst active under visible light. The $\mathrm{CuO}$ acts as sink for photogenerated electrons, prevents recombination and thus enhances the redox reaction and hence the efficiency of the degradations. 


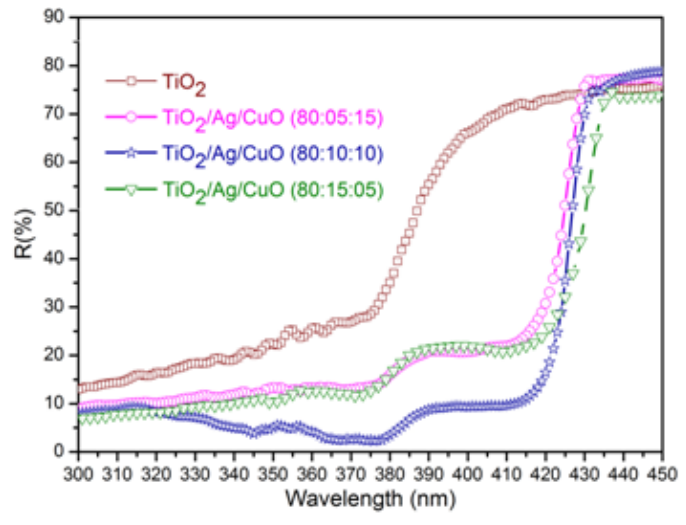

FIG. 3. Diffuse reflectance spectrum of the prepared photocatalysts

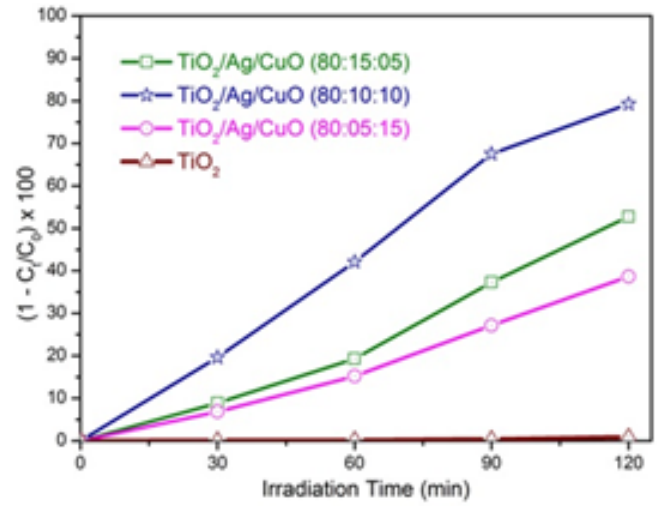

FIG. 4. Degradation profile - Methylene Blue

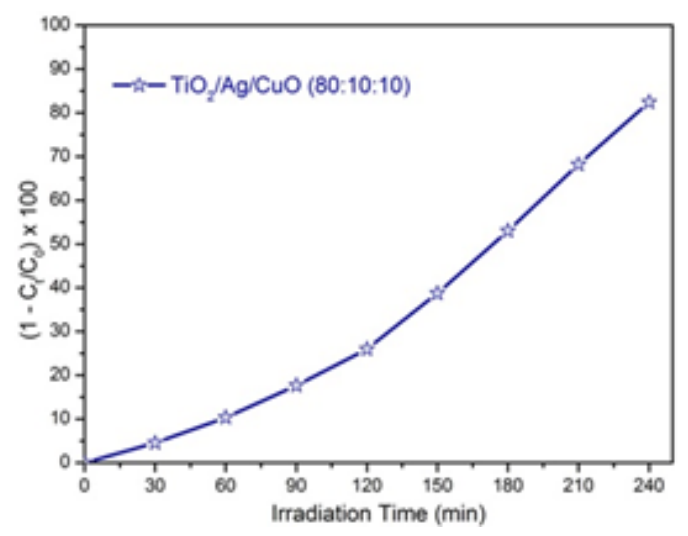

FIG. 5. Degradation profile - Textile Effluent

\section{Acknowledgements}

One of the authors, NK, thanks HETC project for the financial support. The authors are thankful to SAIF at IIT Chennai for the HR-TEM and UV-Vis DRS characterization of powder samples.

\section{References}

[1] Fujishima A., Honda K. Electrochemical Photolysis of Water at a Semiconductor Electrode. Nature, 1972, 238 (5358), P. $37-38$.

[2] Hisaindee S., Meetani M.A., Rauf M.A. Application of LC-MS to the analysis of advanced oxidation process (AOP) degradation of dye products and reaction mechanisms. TrAC Trends in Analytical Chemistry, 2013, 49, P. 31-44.

[3] Chequer F.M.D., et al. Analyses of the genotoxic and mutagenic potential of the products formed after the biotransformation of the azo dye Disperse Red 1. Toxicology in Vitro, 2011, 25 (8), P. 2054-2063.

[4] Parsons S.A., Williams M. Advanced Oxidation Processes for Water and Wastewater. London, UK: IWA Publishing, 2004,368 p.

[5] Jakob M., Levanon H., Kamat P.V. Charge Distribution between UV-Irradiated $\mathrm{TiO}_{2}$ and Gold Nanoparticles:? Determination of Shift in the Fermi Level. Nano Letters, 2003, 3 (3), P. 353-358.

[6] Wood A., Giersig M., Mulvaney P. Fermi Level Equilibration in Quantum Dot?Metal Nanojunctions. The Journal of Physical Chemistry $B, 2001,105$ (37), P. 8810-8815.

[7] Anh Tuan V., et al. Synthesis and characterization of $\mathrm{TiO}_{2}$ photocatalyst doped by transition metal ions $\left(\mathrm{Fe}^{3+}, \mathrm{Cr}^{3+}\right.$ and $\left.\mathrm{V}^{5+}\right)$. Advances in Natural Sciences: Nanoscience and Nanotechnology, 2010, 1 (1), P. 015009 (4 p).

[8] Rehman S., et al. Strategies of making $\mathrm{TiO}_{2}$ and $\mathrm{ZnO}$ visible light active. Journal of Hazardous Materials, 2009 , 170 (2-3), P. $560-569$.

[9] Qiu R., et al. Photocatalytic activity of polymer-modified ZnO under visible light irradiation. J. Hazardous Mat., 2008 , 156 (1-3), P. 80-85.

[10] Saravanan R., et al. Photocatalytic Degradation of Organic Dyes Using ZnO/CeO2 Nanocomposite Material Under Visible Light. Advanced Materials Research, 2012, 584 (1), P. 381-385.

[11] Karthikeyan N., Narayanan V., Stephen A. Effect of Annealing on Photocatalytic Degradation of $\mathrm{Azo}_{\mathrm{Dye}}$ by TiO $2 / \mathrm{CuO}$ Binary Nanostructured Materials. 4th Int. Symp. for Research Scholars on Metallurgy, Materials Science and Engineering. ISRS, 2012.

[12] Karthikeyan N., Narayanan V., Stephen A. Synthesis and Characterization of Coupled ZnO/Ag/CuO Nanomaterials for Photocatalytic Degradation of Organic Dye under UV irradiation. Int. J. Inn. Res. Sci. \& Eng., 2014, 2 (spl), P. 74-79. 